Revista Tecné, Episteme y Didaxis: TED. Año 2014, Número Extraordinario. ISSN Impreso: 0121-3814, ISSN web: 2323-0126

Memorias, Sexto Congreso Internacional sobre Formación de Profesores de Ciencias. 08 al 10 de octubre de 2014, Bogotá

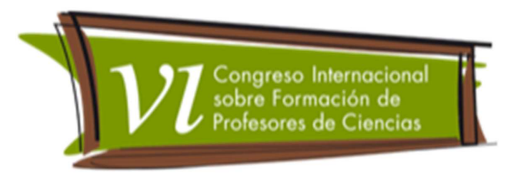

\title{
A história da ciência e a biogênese: Uma análise dos livros didáticos
}

Garcia Mara Cristina de Morais', Santos Sayonara Martins dos²

Categoria 2. Trabalhos de investigação

\section{Resumo}

A inserção da história da ciência no ensino de ciências, como explicação da natureza do conhecimento cientifico, pode contribuir para superação de visões deformadas da ciência, como aquelas que a entendem como individual, elitista e linear. O presente trabalho objetiva analisar a presença da História da Ciência nos livros didáticos de ciências aprovados pelo Programa Nacional do Livro Didático 2014 (PNLD). Frente a isto investigamos a seguinte questão: A teoria da biogênese nos livros didáticos é contextualizada historicamente? A forma que esta é apresentada pode contribuir com a superação das visões deformadas de ciência?

\section{Palavras chave}

Livro didático; História da Ciência; Biogênese; Pasteur; Pouchet.

\section{Objetivo}

Analisar a presença ou ausência da história da ciência nos livros didáticos de ciências das séries finais do ensino fundamental (ensino fundamental II) aprovados pelo Plano Nacional do Livro Didático do Brasil.

\section{Marco Teórico}

Os referenciais teóricos que estudam o ensino de ciências apontam para uma "crise" neste ensino visto que a ciência tem sido apresentada de forma linear, elitista e descontextualizada (Pozo e Crespo, 2009, Fourez, 1997, Chapuz et al,

\footnotetext{
1 Mestranda no Programa de Educação em Ciências e Matemática (MECM) da Universidade Federal de Goiás (UFG). Email: mcmgcelestino@hotmail.com

2 Mestranda no Programa de Educação em Ciências e Matemática (MECM) da Universidade Federal de Goiás (UFG). Email: sayonaramds@hotmail.com
} 
Revista Tecné, Episteme y Didaxis: TED. Año 2014, Número Extraordinario. ISSN Impreso: 0121-3814, ISSN web: 2323-0126 Memorias, Sexto Congreso Internacional sobre Formación de Profesores de Ciencias. 08 al 10 de octubre de 2014, Bogotá

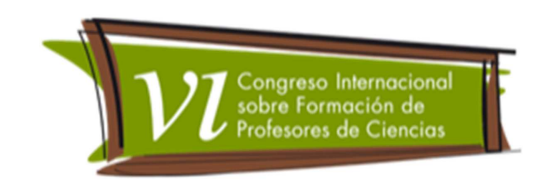

2011). Esta crise perpassa décadas, reformulações de currículos, construção de parâmetros curriculares e não se percebe significativa melhora. Em conformidade com as avaliações internacionais, os jovens brasileiros não conseguem associar as informações científicas na construção dos seus saberes. (Academia Brasileira de Ciências, 2008).

Uma alternativa para responder a essa crise é a utilização da História da Ciência (HC) nas aulas de ciências, já que a mesma pode ser utilizada em qualquer nivel de ensino. Matthews (1994) apresenta sete razões para a inclusão da HC no ensino de ciências: promove a melhor compreensão de conceitos e métodos científicos; conectam o desenvolvimento do pensamento individual com 0 desenvolvimento das ideias científicas; familiariza o estudante com a valiosa História; é necessária para o entendimento da natureza da ciência; neutraliza o cientificismo e o dogmatismo presentes nos manuais de ensino; humaniza a ciência; expõe a natureza interativa e interdependente das aquisições humanas.

Através da inserção da história da ciência no ensino de ciências poder-se-ia combater a disseminação do mito de que uma descoberta ou uma teoria é obra de uma única pessoa (Dupuis e Pavão, 2010). A construção do conhecimento científico se torna mais fácil se a história das "descobertas" for descortinada. Dessa forma, os alunos, se apropriando do conhecimento científico, ficam naturalmente estimulados para novas descobertas, contribuindo para 0 aperfeiçoamento da visão acerca do mundo e seus fenômenos. Além disso, a história da ciência pode estimular o reconhecimento de que a Ciência é uma produção humana e que está impregnada de valores e interesses sociais que constantemente são revisados.

A História da Biogênese foi selecionada para a análise de sua presença nos livros didáticos devido à sua relevância enquanto campo do saber da Biologia. No século XIX houve um fervor de vários debates e experimentos que foram feitos com a finalidade de comprovar a origem dos seres vivos. Costuma-se dizer que foi Louis Pasteur (1822-1895) quem derrubou a teoria da Abiogênese e instaurou definitivamente a teoria da Biogênese, baseando-se em uma série de experimentos. Entretanto, uma história menos positivista revela que as coisas não ocorreram dessa forma, ou seja, um experimento não foi capaz de resolver a controvérsia sobre abiogênese e biogênese (Martins, 2009). Além disso, ainda hoje são feitos questionamentos sobre o surgimento dos primeiros seres vivos no planeta. 
Revista Tecné, Episteme y Didaxis: TED. Año 2014, Número Extraordinario. ISSN Impreso: 0121-3814, ISSN web: 2323-0126

Memorias, Sexto Congreso Internacional sobre Formación de Profesores de Ciencias. 08 al 10 de octubre de 2014, Bogotá

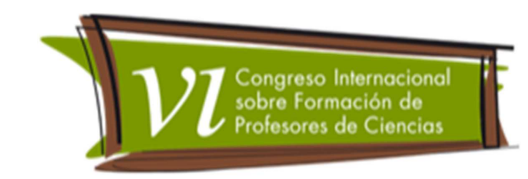

Frente a importância da utilização da $H C$ no ensino e sua utilização como fundamento normativo no Programa Nacional do Livro Didático (PNLD) (Brasil, 2013), analisaremos neste artigo a presença da HC nos livros didáticos das séries finais do ensino fundamental aprovados pelo PNLD para o ano de 2014. Mais precisamente, analisaremos a História da Biogênese, com a finalidade de averiguar se a história presente é não linear e contextualizada, que vá além de nomes e datas, conforme exigência do PNLD. Encontramos esse conteúdo nos livros do sétimo ano das séries finais do ensino fundamental.

\section{Metodologia}

Foram analisados oito livros de ciências das séries finais do ensino fundamental aprovados na avaliação do Ministério de Educação e Cultura (MEC) do território brasileiro para o ano de 2014. Estas amostras foram selecionadas vistas serem as que foram disponibilizadas o acesso em uma instituição de ensino do município de Goiânia. O período de analise foi de janeiro a março de 2014. Foram analisadas as seguintes obras:

(1) Canto, E. L. (2012). Ciências naturais: aprendendo com o cotidiano: ciências, 7ํano: ensino fundamental. 4 ed. São Paulo: Moderna.

(2) Moretti, R. (2012). Ciências nos dias de hoje: ciências, 7ํa ano: ensino fundamental. 1 ed. São Paulo: Leya.

(3) Gowdak, D. O.; Martins, E. L. (2012). Ciências novo pensar - Edição renovada: seres vivos, 7o ano: ensino fundamental. 1 ed. São Paulo: FTD.

(4) Usberco, J., (et al.) (2012). Companhia das ciências: ciências, 7o ano: ensino fundamental. 2 ed. São Paulo: Saraiva.

(5) Costa, A.; Scrivano, C. N. (2012). Oficina do saber: ciências, 7º ano: ensino fundamental. 1 ed. São Paulo: Leya.

(6) Aguilar, J. B. (2012). Para viver juntos: ciências, 7o ano: ensino fundamental. 3 ed. São Paulo: Edições SM.

(7) Projeto Araribá: ciências (2010). Organizadora Editora Moderna; obra coletiva concebida, desenvolvida e produzida pela editora moderna; editora responsável: Vanessa Shimabukuro - 3 ed. São Paulo: Moderna. 
Revista Tecné, Episteme y Didaxis: TED. Año 2014, Número Extraordinario. ISSN Impreso: 0121-3814, ISSN web: 2323-0126

Memorias, Sexto Congreso Internacional sobre Formación de Profesores de Ciencias. 08 al 10 de octubre de 2014, Bogotá

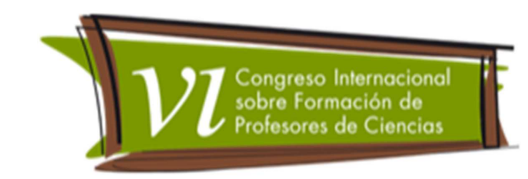

(8) Gewandsznajder, F. (2011). Projeto Teláris: ciências 7º ano: ensino fundamental. 1. ed. São Paulo: Ática.

Analisamos o capitulo referente à origem da vida, em especial à teoria da biogênese. Para a análise dos dados utilizamos a metodologia da análise de conteúdo proposta por Bardin (1994).

\section{Resultados}

Para a análise da HC presente nos oito livros didáticos aprovados pelo PNLD que tivemos acesso, construímos e utilizamos quatro categorias de análise: (1) ausência da história; (2) presença de nomes e datas; (3) presença de história linear; (4) presença da história contextualizada. Essas categorias emergiram do processo de análise, exploração e interpretação dos capítulos dos livros didáticos que abordavam ou deveriam abordar a Biogênese no conteúdo da Origem dos Seres Vivos.

A categoria 1, ausência da História, compreende a falta de qualquer comentário sobre a $\mathrm{HC}$ ao longo do texto didático.

A categoria 2, presença de nomes e datas, em relação à $\mathrm{HC}$, compreende a citação do nome do cientista que realizou determinado experimento e/ou descoberta bem como a data em que os mesmos foram realizados.

A categoria 3, presença de história linear (quase-história), compreende a caricatura da História. É a História contada como se todos os acontecimentos tivessem ocorrido de forma sequencial, sem interrupções, graças à genialidade de um cientista que de maneira simples chegou a uma conclusão que modificou os caminhos da ciência.

Finalmente, a categoria 4, presença da história contextualizada, compreende a História real. É a HC contada a partir do contexto das descobertas científicas. Aborda o histórico das descobertas, as controvérsias que permeavam o momento e os paradigmas adotados pela Academia Científica da época (Praia et al, 2007).

Os livros que compõem nossa amostra foram enumerados de 1 a 8 e, em relação à História da Biogênese, foram classificados da seguinte maneira: 
Revista Tecné, Episteme y Didaxis: TED. Año 2014, Número Extraordinario. ISSN Impreso: 0121-3814, ISSN web: 2323-0126 Memorias, Sexto Congreso Internacional sobre Formación de Profesores de Ciencias. 08 al 10 de octubre de 2014, Bogotá

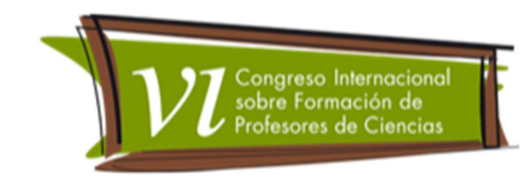

Os livros 1, 2, 3 e 5, foram incluídos na categoria 1 por não apresentarem a HC. Dessa forma, não contemplaram dois dos critérios de avaliação do livro didático segundo o PNLD, a saber, que trata da produção do conhecimento científico como sendo uma obra coletiva no que se refere a pessoas e instituições e o que exige a presença da HC além de nomes e datas, com a exploração do contexto em que ocorreu a produção.

Os livros 4, 6, 7 e 8, foram incluídos nas categorias 2 e 3. Neles observamos a presença de uma quase-história. Apesar da quase-história ir além da presença de nomes e datas, ela é uma falsificação da história, já que se apresenta como uma história genuína que procura sustentar uma determinada versão de metodologia científica na qual as figuras históricas são retratadas à luz da metodologia ortodoxa atual. Na construção do conhecimento do aluno, essa quase-história forma visões distorcidas da ciência.

A produção de uma história simplificada, que leve em consideração a faixa etária dos alunos e todo o currículo a ser desenvolvido é necessária, mas isso não significa a disponibilização de uma história caricaturesca, de uma quase-história que se resume a aspectos cronológicos. Os textos didáticos dos livros dessas coleções mencionam Pasteur como sendo aquele que "provou conclusivamente" que a geração espontânea não existe. Nestes textos, os autores afirmam que, depois dos experimentos de Pasteur, todos aceitaram suas conclusões. Pouchet, outro importante cientista da época, não foi mencionado em nenhum livro. Dessa forma, os estudantes ficam com a impressão errônea de que tudo estava perfeitamente claro na época e que os únicos experimentos existentes eram contrários à geração espontânea. Trechos de dois livros demonstram essa quase-história:

Foi apenas no início da década de 1860 que o cientista francês Louis Pasteur (1822-1895) conseguiu provar que os microrganismos também só poderiam surgir de outros microrganismos. (...) Com essa experiência, Pasteur derrubou definitivamente a teoria da geração espontânea. (livro 4, pág. 72)

Em 1862, o químico francês Louis Pasteur realizou novos experimentos. (...) então concluiu que os microrganismos estavam no ar (...) desde então prevalece a teoria de que, nas atuais condições terrestres, um ser vivo só se origina a 
Revista Tecné, Episteme y Didaxis: TED. Año 2014, Número Extraordinario. ISSN Impreso: 0121-3814, ISSN web: 2323-0126

Memorias, Sexto Congreso Internacional sobre Formación de Profesores de Ciencias. 08 al 10 de octubre de 2014, Bogotá

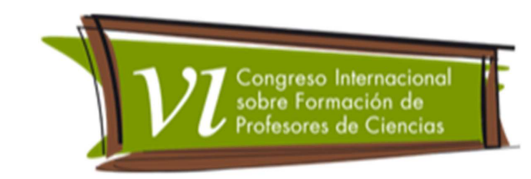

partir de outro, processo chamado de biogênese. (Livro 7, pág. 65)

Outros fatores que contribuem para que os alunos continuem com a visão equivocada da ciência em relação à Biogênese é a ausência dos fatores históricos, por exemplo, em relação à publicação da teoria evolucionista de Darwin que ocorreu na mesma época; a posição política de Pasteur perante o Imperador Napoleão III; o poder da Igreja Católica; e a posição da Academia de Ciências naquele momento. Então, os autores dos livros didáticos deixaram de lado os fatores extra científicos como as crenças políticas, religiosas e filosóficas dos cientistas envolvidos na história real.

Nenhuma outra História se fez presente nos livros didáticos e, portanto, nenhum livro didático foi incluído na categoria 4. Nesse sentido observamos que, apesar da $\mathrm{HC}$ ser ressaltada no PNLD como categoria de aprovação dos livros didáticos, a história contextualizada não se fez presente nos livros analisados.

\section{Considerações Finais}

A História da Biogênese é diferente da história presente nos livros didáticos. A avaliação dos livros didáticos, mesmo seguindo os critérios do PNLD, apresentam falhas graves em relação à presença da HC. Falhas puderam ser claramente observadas nos livros do sétimo ano, das séries finais do ensino fundamental, quando analisados à luz das categorias de análise empregadas.

Apontamos que a inserção da HC pode contribuir com a contextualização do conhecimento cientíico, entretanto a forma que a historia se faz presente nos livros didáticos analisados não contribui para tal. Ressaltamos a necessidade de maior rigor nas avaliações dos livros didáticos de ciências por parte dos órgãos responsáveis quanto à presença da história do conhecimento cientifico, já que o programa vigente não alcança os objetivos propostos.

Salientamos que o professor pode auxiliar no processo de contextualização do conhecimento cientifico, estimulando a pesquisa vinculada da Historia da Ciência por permitir o acesso a importantes aspectos que ficam ocultos na abordagem tradicional e possibilita elucidar diferentes visões distorcidas da ciência. 
Revista Tecné, Episteme y Didaxis: TED. Año 2014, Número Extraordinario. ISSN Impreso: 0121-3814, ISSN web: 2323-0126

Memorias, Sexto Congreso Internacional sobre Formación de Profesores de Ciencias. 08 al 10 de octubre de 2014, Bogotá

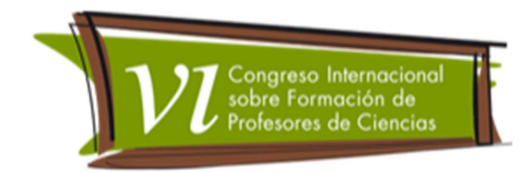

\section{Referências Bibliográficas}

Academia Brasileira de Ciências (2008). O Ensino de ciências e a educação básica: propostas para superar a crise. Rio de Janeiro.

Bardin, L. (1994). Análise de conteúdo. Lisboa: Edições 70.

Bastos, F. (1998). História da Ciência e Ensino de Biologia: a pesquisa médica sobre a febre amarela (1881-1903). São Paulo. 212p. Tese (Doutorado em Educação) -Faculdade de Educação, Universidade de São Paulo.

Bizzo, N. (1992). História da Ciência e ensino: onde terminam os paralelos possiveis? In: Em Aberto, Brasília, ano 11 (55), págs. 29-35.

Brasil.(2013). Guia de livros didáticos: PNLD 2014. Ciências: ensino fundamental: anos finais. Ministério da Educação, Secretaria de Educação Básica, Brasilia.

Cachapuz, A. (2011). A necessária renovação do ensino das ciências. Ed. Cortez. $2^{\mathrm{a}}$ ed. São Paulo.

Dupuis, F. A. R.; Pavão, A. C. (2010). Ensinar ciências através da história - Mitos e meandros na construção do conhecimento. In: Coleção explorando o ensino, v. 18. Braślia: Ministério da Educação, Secretaria de Educação Básica. 212 págs. 159 - 178

Duschl, R.A. (1985). Science education and philosophy of Science: twenty-five years of mutually exclusive development. School Science and Mathematics, Jacksonville, Florida 85 (7): 541 - 555.

Fourez, G. (1997). Alfabetización científica y tecnológica. Acerca de las finalidades de la enseñanza de las ciências. Colihue. Buenos Aires.

Matthews, M. (1994). Science teaching: the role of history and philosophy of Science. New York: Routledge.

Martins, L. A. P. (2013). Pasteur e a geração espontânea: uma história equivocada. Filosofia e História da Biologia, São Paulo v. 4, p. 65 - 100, 2009. Disponivel em: http://www.abfhib.org/FHB/FHB-v04.html. Acesso em: 30 de agosto de 2013. 
Revista Tecné, Episteme y Didaxis: TED. Año 2014, Número Extraordinario. ISSN Impreso: 0121-3814, ISSN web: 2323-0126

Memorias, Sexto Congreso Internacional sobre Formación de Profesores de Ciencias. 08 al 10 de octubre de 2014, Bogotá

Martins, R. A.(1990). Sobre o papel da história da ciência no ensino. Boletim da Sociedade Brasileira de História da Ciência (9): 3-5.

Praia, J.; Gil-Perez, D. I.; Vilshes, A. (2007). O papel da Natureza da Ciência na Educação para a Cidadania. Clência \& Educação, v .13, n.2, págs.141-156, Bauru.

Pozo, J. I.; Crespo, M. A. G. (2009). A aprendizagem de ciências: do conhecimento cotidiano ao conhecimento científico. 5 ed. Porto Alegre: Artme. 